\title{
A Young Person With Recurrent Severe Hypokalaemia - Familial, latrogenic Or Just Unknown?
}

\author{
Muhammad Shafqat, Navya Basavaraju, Srinivasa Rangan, Prashant Singh, Probal Moulik \\ Department of Endocrinology, Royal Shrewsbury Hospital, Shrewsbury, Shropshire.
}

\section{CASE REPORT}

A 26-year-old female presented with 5-year history of episodic muscle weakness, abdominal cramps and facial paraesthesia. She had 2 hospital admissions elsewhere within 6months with severe hypokalaemia $(1.9 \mathrm{mmol} / \mathrm{L})$. She was started on Lamotrigine for epilepsy 7 years ago and changed to Levetiracetam in October 2010 following further seizures. She is now seizure-free for over 5 years. Her potassium levels before and after Levetiracetam are shown in Table 1.

She had an uneventful childhood. She had no osmotic or urinary symptoms, denied diuretic, laxative, excessive alcohol/liquorice ingestion. No relevant family history. Her body mass index is 22.3 , blood pressure $103 / 55 \mathrm{mmHg}$. Physical examination was unremarkable. Biochemical evaluation is as shown in Table 2.

Her genetic screen is awaited.

\begin{tabular}{|c|c|}
\hline Dates & Potassium (3.5-5.3mmol/L) \\
\hline 18/04/2008 & 3.9 \\
\hline $04 / 10 / 2010$ & 4.3 \\
\hline $30 / 10 / 2010$ & 3.5 \\
\hline $30 / 07 / 2011$ & 2.8 \\
\hline
\end{tabular}

Table 1.

\begin{tabular}{|l|l|}
\hline Serum & Results \\
\hline Sodium & $135 \mathrm{mmol} / \mathrm{L}(133-146)$ \\
\hline Potassium & $2.8 \mathrm{mmol} / \mathrm{L}(3.5-5.3)$ \\
\hline Chloride & $91 \mathrm{mmol} / \mathrm{L}(95-108)$ \\
\hline Bicarbonate & $38 \mathrm{mmol} / \mathrm{L}(22-30)$ \\
\hline Magnesium & $0.76 \mathrm{mmol} / \mathrm{L}(0.70-1.0)$ \\
\hline Aldosterone & $130 \mathrm{pmol} / \mathrm{L}$ \\
\hline Renin & $238 \mathrm{mU} / \mathrm{L}(9.8-33.7)$ \\
\hline Aldosterone/renin ratio & $0.5 \mathrm{pmol} / \mathrm{mU}(0-70)$ \\
\hline Urine Analysis & Results \\
\hline Sodium & $170 \mathrm{mmol} / \mathrm{L}$ \\
\hline Potassium & $82 \mathrm{mmol} / \mathrm{L}$ \\
\hline Chloride & $21 \mathrm{mmol} / \mathrm{L}$ \\
\hline Diuretic \& Laxative screen & Negative \\
\hline
\end{tabular}

\section{Table 2}

\section{DISCUSSION}

In this case with normotensive hypokalemic alkalosis, differential diagnoses are Bartter syndrome (negative family history, normal aldosterone), Gitelman syndrome (no family history, normal magnesium), diuretic use (negative urine screen), laxative abuse (history), normotensive primary hyperaldosteronism (normal aldosterone).

Given the sequence of results, most likely cause of severe hypokalaemia is Levetiracetam. She declined temporary withdrawal of Levetiracetam due to risk of seizure recurrence affecting driving and job. She remains on spironolactone and potassium supplements.

Our literature search yielded only two case-reports $[1,2]$ of Levetiracetam-induced hypokalaemia involving 3 patients all of whom had additional hypomagnesaemia.

\section{CONCLUSIONS}

To our knowledge, this is the only report of Levetiracetaminduced severe life-threatening isolated hypokalaemia. Levetiracetam is increasingly used for epilepsy and further studies on the prevalence of life threatening electrolyte imbalance are required to guide biochemical surveillance.

\section{REFERENCES}

1. Vallianou NG, Geladari E, Chroni P, Kokkinakis E. Levetiracetam-associated Hypokalemia and Hypomagnesaemia among Two Patients Treated for Seizures. CNS Neurosci Ther. 2015 Jun;21(6):539.

2. Aksoy D, Cevik B, Kurt S, Pekdas E, Solmaz V. Hypokalemia and hypomagnesaemia related to levetiracetam use. J Clin Neurosci. 2014 Nov;21(11):1989-90. 